\title{
Pengaruh Strategi Card Sort Berbantu Media Gambar terhadap Prestasi Belajar IPA
}

\author{
Asteria Lindiyana Anggreani1* ${ }^{*}$, Choirul Huda ${ }^{2}$, Eka Sari Setianingsih ${ }^{3}$ \\ 1,2,3 Jurusan Pendidikan Guru Sekolah Dasar (PGSD), Fakultas Ilmu Pendidikan, Universitas PGRI Semarang.
}

\author{
A R T I C L E I N F O \\ Article history: \\ Received 20 August 2018 \\ Received in revised form \\ 9 September 2018 \\ Accepted 15 October 2018 \\ Available online 25 \\ November 2018

Kata Kunci:
Strategi card sort, Med
gambar,Prestasi belajar, IPA
Keywords:
card sort strategy, image
media, learning
achievement, science

\begin{abstract}
A B S T R A K
Pengaruh Strategi Card Sort Berbantu Media Gambar Terhadap Prestasi Belajar IPA Kelas IV SDN Bumirejo 1 Karangawen Demak Tahun Ajaran 2018/2019. Penelitian ini bertujuanuntuk mengetahui pengaruh strategi Card Sort berbantu media gambar terhadap prestasi belajar IPA kelas IV SDN Bumirejo 1 Karangawen Demak Tahun Ajaran 2018/2019. Jenis penelitian ini adalah penelitian kuantitatif dengan desain Pre Eksperimental Design dan jenis yang diambil adalah OneGroup Pretest-Posttest Design. Sampel yang diambil adalah 18 siswa kelas IV dengan menggunakan teknik Non Probability Sampling dengan sampling jenuh. Hasil penelitian menunjukkan hasil posttest yaitu dari 18 siswa yang tuntas sebanyak 13 siswa atau $72,2 \%$ mencapai KKM sedangkan siswa yang tidak tuntas sebanyak 5 siswa atau $27,8 \%$. Sedangkan hasil pretest dari 18 siswa hanya 6 atau 33,3\% yang mencapai KKM sedangkan yang tidak tuntas sebanyak 12 siswa atau $66,7 \%$. Hasil analisis uji $t$ diperoleh $t_{\text {hitung }}=6,3060$ dan $t_{\text {tabel }}=1,740$. Karena $t_{\text {hitung }}>t_{\text {tabel }}$ yaitu 6,3060 $>1,740$ maka sesuai dengan rumusan hipotesis yang diujikan, $\mathrm{H}_{0}$ ditolak dan $\mathrm{H}_{\mathrm{a}}$ diterima, kesimpulan bahwa strategi Card Sort berbantu media gambar berpengaruh terhadap prestasi belajar IPA siswa kelas IV SDN Bumirejo 1 Karangawen Demak.
\end{abstract}

\section{A B S T R A C T}

The Influence of Media-assisted Card Sort Strategies on Learning Achievement in Science Class IV SDN Bumirejo 1 Karangawen Demak Academic Year 2018/2019. This study aims to determine the effect of the media image-assisted Card Sort strategy on learning achievement of science grade IV SDN Bumirejo 1 Karangawen Demak Academic Year 2018/2019. This type of research is a quantitative research with the Pre Experimental Design design and the type taken is One-Group Pretest-Posttest Design. The samples taken were 18 fourth grade students using Non Probability Sampling technique with saturated sampling. The results showed the posttest results of 18 students who completed as many as 13 students or $72.2 \%$ achieved KKM while students who did not complete as many as 5 students or $27.8 \%$. While the pretest results from 18 students were only 6 or $33.3 \%$ who achieved KKM while the incomplete were 12 students or $66.7 \%$. The results of the $t$ test analysis obtained tcount $=6.3060$ and $t$ table $=1.740$. Because thitung $>t$ table is $6.3060>1.740$ then in accordance with the formulation of the hypothesis tested, $\mathrm{Ho}$ is rejected and $\mathrm{Ha}$ is accepted, the conclusion that the image media assisted Card Sort strategy influences the science learning achievement of fourth grade students of SDN Bumirejo 1 Karangawen Demak. 


\section{Pendahuluan}

Pendidikan yang tercantum dalam Undang-Undang Nomor 20 Tahun 2003 Pasal 1 tentang Sistem Pendidikan Nasional menyatakan bahwa: "Pendidikan adalah usaha sadar dan terencana untuk mewujudkan suasana belajar dan proses pembelajaran agar peserta didik secara aktif mengembangkan potensi dirinya untuk memiliki kekuatan spiritual keagamaan, pengendalian diri, kepribadian, kecerdasan, akhlak mulia, serta keterampilan yang diperlukan dirinya, masyarakat, bangsa dan Negara".

Merujuk dari pengertian tersebut pendidikan adalah usaha sadar dan terencana untuk mewujudkan suasana belajar yang nyaman, menyenangkan agar dapat menciptakan proses pembelajaran dengan efektif dan efisien. Dengan adanya pendidikan, setiap individu dapat mengembangkan potensi yang dimiliki sehingga dapat tercipta sumber daya manusia yang baik dan berkualitas untuk menunjang kemajuan bangsa.

Pendidikan merupakan salah satu perwujudan kebudayaan manusia yang dinamis dan berkembang supaya ada perubahan, perubahan dalam arti perbaikan pendidikan pada semua tingkat yang terus menerus demi kepentingan masa depan. Pendidikanbaikakan menghasilkan generasi penerus bangsa yang berkualitas dalam bidang pengetahuan dan keterampilan, mampu berpikir kreatif, kritis dan terbuka.Dalammeningkatkan kualitas pendidikan di Indonesia, hal ini pemerintah berusaha meningkatkan dan mengembangkan pendidikan di Indonesia. Salah satunya denganmengembangkan kurikulum sebagai instrumen yang membantu pemerintah untuk menjalankan pendidikan di Indonesia.Pendidikan di sekolah dilaksanakan melalui proses pembelajaran dengan mengikuti kurikulum yang berlaku. Berdasarkan Permendiknas No.22 Tahun 2006 Pasal 1 dalam struktur kurikulum SD/MI meliputi subtansi pembelajaran yang ditempuh dalam satu jenjang pendidikan selama enam tahun mulai kelas 1 sampai kelas VI. Struktur kurikulum SD/MI disusun berdasarkan standar kompetensi lulusan dan standar kompetensi mata pelajaran, salah satunya mata pelajaran Ilmu Pengetahuan Alam (IPA).

Mata pelajaran Ilmu Pengetahuan Alam (IPA) mencari tahu tentang alam secara sistematis, sehingga Ilmu Pengetahuan Alam (IPA) bukan hanya penguasaan kumpulan pengetahuan yang berupa fakta-fakta, konsep-konsep atau prinsip-prinsip saja tetapi Ilmu Pengetahuan Alam (IPA) merupakan suatu proses penemuan. Ilmu Pengetahuan Alam (IPA) diperlukan dalam kehidupan sehari-hari untuk memenuhi kebutuhan manusia melalui pemecahan masalah-masalah yang dapat diidentifikasikan. Penerapan Ilmu Pengetahuan Alam (IPA) perlu dilakukan secara bijaksana agar tidak berdampak buruk terhadap lingkungan. Pembelajaran Ilmu Pengetahuan Alam (IPA) sebaiknya dilaksanakan secara inkuiri ilmiah (scientific inquiry) untuk menumbuhkan kemampuan berfikir, bekerja, dan bersikap ilmiah serta mengkomunikasikan sebagai aspek penting kecakapan hidup. Oleh karena itu pembelajaran Ilmu Pengetahuan Alam (IPA) di SD menekankan pada pemberian pengalaman belajar secara langsung melalui penggunaan dan pengembangan keterampilan proses dan sikap ilmiah. Dalam kegiatan pembelajaran guru perlu menggunakan dan memanfaatkan strategi pembelajaran sebagai sistem dalam pembelajaran agar siswa lebih mudah memahami materi dan tidak merasa jenuh dalam pembelajaran.

Berdasarkan wawancara yang dilakukan di kelas IV di SDN Bumirejo 1 Karangawen Demakdiketahui bahwa 4 dari 18 siswa yang mampu memperoleh nilai diatas Kriteria Ketuntasan Minumum (KKM). Pada mata pelajaran Ilmu Pengetahuan Alam (IPA) ada beberapa siswa yang beranggapan bahwa mata pelajaranIlmu Pengetahuan Alam (IPA) sulit dipahami jika dibandingkan dengan mata pelajaran yang lain anggapan tersebut dapat mempengaruhi mental siswa dan juga dapat menimbulkan sikap negatif siswa terhadap Ilmu Pengetahuan Alam (IPA). Karena guru dalam menyampaikan pembelajaran masih menggunakan model ceramah belum sepenuhnya menggunakan model, strategi, dan media pembelajaran sehingga siswa merasa bosan dan jenuh dengan pembelajaran yang monoton dan kurang menarik menjadikan semangat belajar siswa berkurang dan dampaknya siswa menjadi kurang tertarik untuk mengikuti pelajaran Ilmu Pengetahuan Alam (IPA) dikarenakan guru belum bervariasi dalam menggunakan model, strategi, dan media pembelajaran. Anggapan tersebut terjadi pada siswa yang memiliki kemampuan yang rendah dan yang mudah putus asa. Siswa yang seperti itu biasanya tidak yakin pada kemampuannya dan beranggapan bahwa dirinya tidak akan mampu untuk mempelajari dan menguasai mata pelajaran Ilmu Pengetahuan Alam (IPA). Demikian untuk mengatasi permasalahan-permasalahan di atas, sebagai alternatif dapat diterapkan Strategi Card Sort.

Strategi pembelajaran yang peneliti terapkan adalah strategi Card Sort berbantu media gambar. Dengan demikian, pemilihan strategi Card Sort berbantu media gambar untuk meningkatkan pemahaman siswa terhadap materi pembelajaran dan materi pembelajaran lebih mudah tersampaikan kepada siswa. Strategi Card Sort merupakan kegiatan kolaboratif yang bisa digunakan untuk 
mengajarkan konsep, penggolongan, sifat, fakta, tentang suatu obyek, atau mengulang informasi. Gerakan fisik yang dilakukan siswa dapat membantu untuk memberi energi kepada kelas yang telah letih (Hamruni, 2012: 167). Adapun bentuk Card Sort yaitu kartu tersebut berupa potongan-potongan kertas yang dibentuk seperti kartu yang berisi tentang informasi atau materi pelajaran yang dibedakan menjadi dua kartu yaitu kartu yang pertama adalah berupa tulisan materi dan kartu yang kedua berupa gambar. Kelebihan dari strategi Card Sort antara lain (1) Siswa lebih mudah menerima materi dibanding dengan menggunakan model ceramah (2) Siswa bersemangat dan antusias dalam pembelajaran (3) Meminimalisir model ceramah yang menyebabkan dan membuat siswa jenuh cepat bosan (4) Sosialisasi siswa terlihat dan terbangun yakni siswa lebih akrab dan lebih berani setelah menggunakan strategi pembelajaran ini. Adapun kelemahan-kelemahan strategi Card Sort adalah sebagai berikut adanya kemungkinan terjadi penyimpangan perhatian siswa, terutama apabila terjadi jawaban-jawaban yang menarik perhatiannya, padahal bukan sasaran (tujuan) yang diinginkan dalam arti terjadi penyimpangan dari pokok persoalan semula. Sakdiyah (2016) menyatakan bahwa melalui penerapan model pembelajaran aktif tipe Card Sort dapat merangsang keterlibatan siswa dalam kegiatan pembelajaran. Keterlibatan tersebut adalah keterlibatan secara fisik maupun mental yang keduanya saling berkaitan satu sama lain. Anggayuni 2013 berpendapat bahwa Penggunaan strategi pembelajaran tipe Card Sort diharapkan dapat memberikan semangat kepada peserta didik pada pembelajaran IPS

Media sebagai alat bantu dalam proses belajar mengajar guru menyadari bahwa tanpa bantuan media, maka bahan pelajaran sukar untuk dicerna dan dipahami oleh setiap siswa, terutama bahan pelajaran yang rumit atau kompleks (Djamarah,2013: 121). Dengan demikian agar strategi Card Sort mudah dipahami siswa strategi Card Sort dibantu dengan menggunakan media gambar. Media gambar/foto merupakan media pembelajaran yang sering digunakan. Media ini merupakan bahasa yang umum, dapatdimengerti, dan dinikmati oleh semua orang di mana-mana. Gambar/foto berfungsi untuk menyampaikan pesan melalui gambar yang menyangkut indera penglihatan. Pesan yang disampaikan dituangkan ke dalam simbol-simbol tersebut perlu dipahami dengan benar agar proses penyampaian pesan dapat berhasil dan efisien (Kustandi \& Sutjipto,2013: 41).

Penggunaan strategi Card Sort berbantu media gambar diharapkan dapat memudahkan siswa dalam memahami materi yang disampaikan dan membantu meningkatkan prestasi belajar. Prestasi belajar di bidang pendidikan merupakan hasil dari pengukuran terhadap siswa yang meliputi faktor kognitif, afektif, dan psikomotorik setelah mengikuti proses pembelajaran yang diukur dengan menggunakan instrumen tes atau instrumen yang relevan.

Hamdani (2011: 137) mengatakan "prestasi adalah hasil dari suatu kegiatan yang telah dikerjakan, diciptakan baik secara individu maupun kelompok. Prestasi tidak akan pernah dihasilkan selama seseorang tidak melakukan kegiatan". Jadi, prestasi belajar hasil pengukuran dari penilaian usaha belajar yang dinyatakan dalam bentuk simbol, huruf maupun kalimat yang menceritakan hasil yang sudah dicapai oleh setiap siswa pada periode tertentu. Faktor-faktor yang Mempengaruhi Prestasi Belajar yaitu faktor dari dalam diri (intern) dan faktor dari luar (ekstern). Faktor internal terdiri dari (1) Kecerdasan (inteligensi), (2) Faktor jasmaniah dan faktor fisiologis, (3) Sikap, (4) Minat, (5) Bakat, (6) Motivasi. Faktor eksternal terdiri dari (1) Keadaan Keluarga, (2) Keadaan sekolah, (3) Lingkungan masyarakat.

Berdasarkan uraian latar belakang diatas dan dalam mengadakan penelitian ini karena melihat pembelajaran Ilmu Pengetahuan Alam (IPA) kelas IV belum kondusif dan masih monoton yang mana guru hanya ceramah dan siswa mendengarkanuntuk memberikan masukan dalam pembelajaran Ilmu Pengetahuan Alam (IPA) sehingga pembelajaran lebih kondusif dan menyenangkan maka peneliti mengajukan judul "Pengaruh Strategi Card Sort Berbantu Media Gambar Terhadap Prestasi Belajar IPA Kelas IV SDN Bumirejo 1 Karangawen Demak Tahun Ajaran 2018/2019".

\section{Metode}

Pelaksanaan kegiatan penelitian pembelajaran dilaksanakan pada semester I di SDN Bumirejo 1 Karangawen Demak. Dalam hal ini penulis mengambil objek penelitiannya yaitu semua siswa kelas IV SDN Bumirejo 1 Karangawen Demak yang terdiri dari 18 siswa. Penelitian ini adalah penelitian kuantitatif dengan desain Pre Eksperimental Design dan jenis yang diambil adalah One Group Pretest Posttest Design. Pretest digunakan untuk mengetahui kondisi awal pada siswa sebelum diberi perlakuan dan setelah itu diberi perlakuan, setelah diberi perlakuan siswa diberi Posttest. 
Tabel 1. Rancangan Desain One-Group Pretest-Posttest Design

\begin{tabular}{llll}
\hline Kelompok & Tes & \multicolumn{1}{c}{ Perlakuan } & Tes \\
\hline Siswa Kelas IV & Pretest & Pembelajaran & Posttest \\
& & menggunakan strategi & \\
& Card Sort berbantu & \\
& media gambar & \\
& & \\
\end{tabular}

Teknik pengumpulan data yang digunakan dalam penelitian ini yaitu tes. Instrumen menggunakan tes (Pretest-Posttest) berupa tes pilihan ganda. Wawancara terstruktur, obervasi dan dokumentasi yang dilakukan dalam kegiatan pembelajaran dikelas.

\section{Hasil dan Pembahasan}

Penelitian ini adalah penelitian kuantitatif dengan desain Pre Eksperimental Design dan jenis yang diambil adalah One Group Pretest Posttest Design. Data penelitian ini terdiri dari data awal yang diperoleh dari nilai pretest dan data akhir yang diperoleh dari nilai posttest.

Untuk menentukan instrumen penelitian maka diperlukan uji coba soal instrumen pada soal pretest dan posttest. Uji coba pada instrumen ini berjumlah 50 butir soal berbentuk pilihan ganda. Kemudian soal tersebut diujikan kepada siswa, setelah dilakukan uji coba soal instrumen kemudian hasil uji coba tersebut diuji dengan uji validitas, reliabilitas, taraf kesukaran, dan daya pembeda. Sehingga dapat diketahui soal yang valid. Pretest merupakan data awal yang diperoleh sebelum siswa diberi perlakuan dengan menggunakan strategi Card Sort berbantu media gambar. Posttest merupakan data akhir yang diperoleh setelah siswa diberi perlakuan dengan menggunakan strategi Card Sort berbantu media gambar.

Dari hasil penelitian di peroleh dari nilai pretest dan posttest. Nilai pretest dan posttest dinyatakan tuntas jika mengalami peningkatan memenuhi KKM serta adanya peningkatan serta adanya peningkatan nilai dari pretest dan posttest setelah diberikan perlakuan hasilnya berbeda. Berikut tabel penjelasan mengenaidata hasil pretest dan posttest kelas IV SDN Bumirejo 1 Karangawen Demak 2018/2019 dapat dilihat pada Tabel 2 .

Tabel 2. Data Hasil Pretest dan Posttest

\begin{tabular}{lll}
\hline Kategori & Pretest & Posttest \\
\hline Nilai terendah & 47 & 60 \\
Nilai tertinggi & 80 & 100 \\
Rata-rata & 62,3 & 80,4 \\
Jumlah siswa yang tidak tuntas & 12 & 6 \\
Jumlah siswa yang tuntas & 5 & 13 \\
Presentase ketuntasan & $33,3 \%$ & $72,2 \%$ \\
\hline
\end{tabular}

Berdasarkan Tabel 2 terdapat perbedaan antara nilai terendah, nilai tertinggi, dan rata-rata. Nilai pretest diperoleh nilai terendah 47 dan nilai tertinggi 80, sedangkan nilai posttest diperoleh nilai terendah 60 dan nilai tertinggi 100. Nilai rata-rata pretest atau sebelum diberi perlakuan sebesar 62,3 setelah diberikan perlakuan dengan strategi Card Sort berbantu media gambar nilai rata-rata posttest siswa yaitu 80,4 . Kemudian pada hasil uji pretest terdapat 12 siswa dari 18 siswa yang belum tuntas dan siswa yang tuntas pada uji pretest terdapat 6 siswa dari 18 siswa. Pada hasil uji posttest terdapat 5 siswa dari 18 siswa yang belum tuntas dan siswa yang tuntas pada uji posttest terdapat 13 siswa dari 18 siswa. Dari data hasil pretest dan posttest ditujukan melalui tabel 2. 


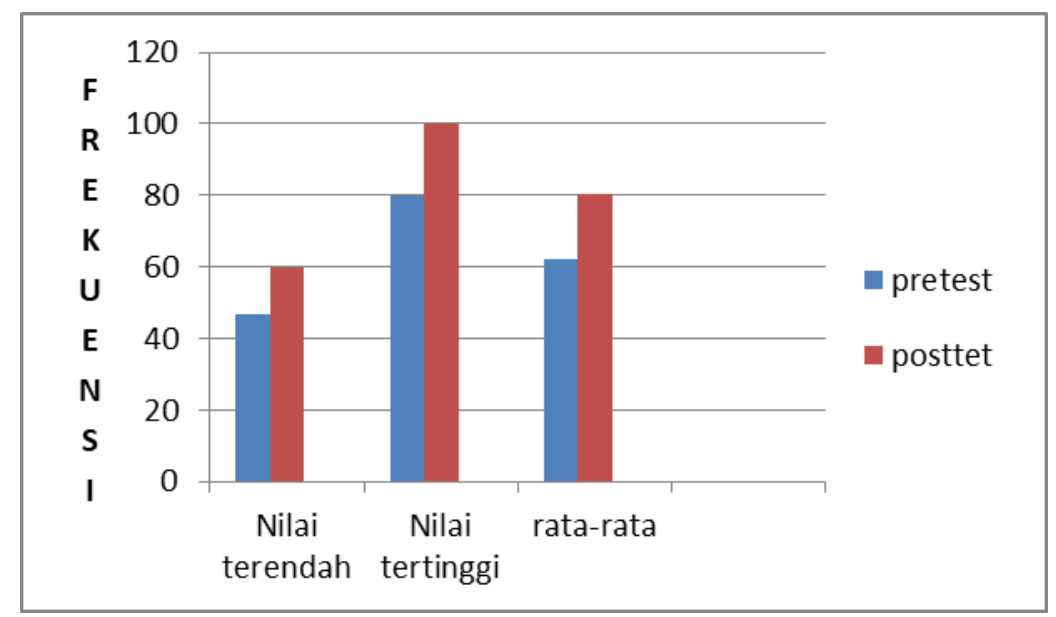

Gambar 1 Diagram Nilai, Rata-Rata Pretest dan Posttest

Berdasarkan diagram 1 dapat diketahui bahwa hasil pretest dan posttest menunjukkan bahwa terdapat peningkatan antara pretest yang sebelum diberikan perlakuan dengan nilai posttest yang sudah diberikan perlakuan dengan strategi Card Sort berbantu media gambar serta ketuntas mencapai KKM.

Setelah mendapatkan data hasil pretest dan posttestakan dilakukan pengujian hipotesis.

Tabel 3. Hasil Uji normalitas Awal

\begin{tabular}{llll}
\hline Kelas & $\mathrm{N}$ & $\mathrm{L}_{0}$ & Kesimpulan \\
\hline Responden & 18 & 0,1799 & $\begin{array}{l}\text { Karena } \mathrm{L}_{0}<\mathrm{L}_{\text {tabel }} \text { yaitu 0,1799<0,2000 maka } \\
\mathrm{H}_{0} \text { diterima, dan data berdistribusi normal. }\end{array}$ \\
\hline
\end{tabular}

Sumber: Data Hasil Penelitian (2018)

Berdasarkan tabel 3 hasil uji nomalitas awal (pretest) setelah mencari harga $L_{\text {tabel }}$ dari nilai kritis uji liliefors dengantaraf signifikan $\alpha=5 \%$ dan $n=18$ diperoleh $L_{\text {tabel }}=0,2000$. Sehingga dapat disimpulkan bahwa $L_{0}<L_{\text {tabel }}$ yaitu: 0,1799<0,2000 maka $\mathrm{H}_{0}$ diterima. Hasil uji normalitas menunjukkan bahwa data pretest siswa berasal dari populasiyang berdistribusi normal.

Tabel 4. Hasil Uji Normalitas Akhir

\begin{tabular}{llll}
\hline Kelas & $\mathrm{N}$ & $\mathrm{L}_{0}$ & Kesimpulan \\
\hline Responden & 18 & 0,1231 & $\begin{array}{l}\text { Karena } \mathrm{L}_{0}<\mathrm{L}_{\text {tabel }} \text { yaitu } 0,1231<0,2000 \text { maka } \mathrm{H}_{0} \\
\text { diterima, dan data berdistribusi normal. }\end{array}$ \\
\hline
\end{tabular}

Sumber: Data Hasil Penelitian (2018)

Berdasarkan tabel 4 hasil uji nomalitas akhir (posttest) setelah mencari harga $L_{\text {tabel }}$ dari nilai kritis uji liliefors dengan taraf signifikan $\alpha=5 \%$ dan $n=18$ diperoleh $L_{\text {tabel }}=0,2000$. Sehingga dapat disimpulkan bahwa $L_{0}<L_{\text {tabel }}$ yaitu: 0,1231<0,2000 maka $\mathrm{H}_{0}$ diterima. Hasil uji normalitas menunjukkan bahwa data pretest siswa berasal dari populasiyang berdistribusi normal.

Tabel 5. Hasil Perhitungan Uji t

\begin{tabular}{llllllll}
\hline Subjek & $\begin{array}{l}\text { Prestasi } \\
\text { Belajar }\end{array}$ & Rata-rata & $\mathrm{N}$ & $\mathrm{Md}$ & $\sum x^{2} d$ & $t_{\text {hitung }}$ & $t_{\text {tabel }}$ \\
\hline $\begin{array}{l}\text { siswa kelas IV SDN Bumirejo } \\
1 \text { Karangawen Demak }\end{array}$ & Pretest & 62,3 & & & & & \\
& Posttest & 80,4 & 18 & 18,2 & 2555.11 & 6.3060 & 1.740 \\
\hline
\end{tabular}


Sumber: Data Hasil Penelitian (2018)

Dari perhitungan uji t di atas dengan $\mathrm{db}=\mathrm{N}-1=18-1=17$ diperoleh $t_{\text {hitung }}=6,3060$. Selanjutnya dikonsultasikan dengan tabel taraf signifikan $5 \%$ dengan $t_{\text {tabel }}=1.740$, maka $t_{\text {hitung }}>t_{\text {tabel }}$. Dengan demikian koefisien $t_{\text {hitung }}$ sebesar 6,3060 adalah signifikan pada taraf 5\%. Atas dasar perhitungan tersebut maka dapat dikatakan bahwa ada pengaruh strategi Card Sort berbantu media gambar terhadap prestasi belajar IPA pada siswa kelas IV SDN Bumirejo 1 Karangawen Demak Tahun Ajaran 2018/2019.

Hasil penelitian ini juga relevan dengan penelitian yang ditulis oleh Haryanto (2011) dari Program Studi Pendidikan Fisika IKIP PGRI Semarang yang berjudul "Pengaruh Strategi Pembelajaran Aktif Card Sort Dan Index Card Match Terhadap Prestasi Belajar Getaran Dan Gelombang". Berdasarkan hasil tulisan dapat disimpulkan bahwa pembelajaran yang dilakukan dengan Strategi Pembelajaran Aktif Card Sort Dan Index Card Match Terhadap Prestasi Belajar Getaran Dan Gelombang, dibuktikan dengan hasil perhitungan $t_{\text {hitung }}=2,461$ dan $t_{\text {tabel }}=1,66$. Karena $t_{\text {hitung }}>t_{\text {tabel }}$ berarti $t_{\text {hitung }}$ berada pada daerah penerimaan $\mathrm{H}_{\mathrm{a}}$. Setelah dilakukan pembuktian antar dua sampel dengan uji $t$ tersebut diperoleh rata-rata hasil tes untuk kelas VIII-A sebesar 74,073 sedangkan rata-rata hasil tes pada kelas VIII-B sebesar 69,756 sehingga dapat disimpulkan bahwa ada perbedaan pengaruh Strategi Pembelajaran Aktif Card Sort dan Index Card Match terhadap prestasi belajar pada materi getaran dan gelombang siswa kelas VIII Semester 2 MTs Futuhiyyah 1 Mranggen Demak Tahun Ajaran 2010/ 2011.

\section{Simpulan dan Saran}

Berdasarkan rumusan masalah, pengajuan hipotesis, analisis data penelitian dan pembahasan, maka diperoleh kesimpulan bahwa prestasi belajar IPA setelah diberi perlakuan dengan strategi Card Sort berbantu media gambar prestasi belajar IPA meningkat. Hal tersebut dapat dibuktikan dengan rata-rata nilai posttest 80,4 lebih tinggi dari rata-rata nilai pretest 62,2 dan ketercapaian prestasi belajar mencapai 18,2. Kemudian dilakukan analisis uji $t$ diperoleh $t_{\text {hitung }}=6.3060>t_{\text {tabel }}=1,740$, maka $\mathrm{H}_{0}$ ditolak dan $\mathrm{H}_{a}$ diterima. Dengan demikian dapat disimpulkan bahwa ada pengaruhstrategi Card Sort berbantu media gambar terhadap prestasi belajar IPA pada siswa kelas IV SDN Bumirejo 1 Karangawen Demak Tahun Ajaran 2018/2019.

\section{Daftar Rujukan}

Amin, C., \& Priyono, A. 2009. Ilmu Pengetahuan Alam jilid 3 untuk SD dan MI Kelas IV. Jakarta: Departemen Pendidikan Nasional.

Anggayuni, Weti. 2013. Pengaruh Strategi Pembelajaran Tpe Card Sort Terhadap Pemerolehan Belajar Ilmu Pengetahuan Sosial Di SD. Untan.Artikel Penelitian. HYPERLINK "http://jurnal.untan.ac.id/index.php/jpdpb/article/view/1894.\%20Diakses\%2013\%20Novembe r\%202017" http://jurnal.untan.ac.id/index.php/jpdpb/article/view/1894. Diakses 13 November $\underline{2017}$ Pukul 20.58 WIB.

Anitah, Sri. 2010. Media Pembelajaran. Surakarta: Yuma Pustaka bekerja sama dengan FKIP UNS.

Arikunto, Suharsimi. 2010. Prosedur Penelitian Suatu Pendekatan Praktik. Jakarta: Rineka Cipta.

Djamarah. 2013. Strategi Belajar Mengajar. Jakarta: Rineka Cipta.

Fakhrurrazi. 2016. "Penerapan Metode Card Sort Dalam Peningkatan Motivasi Dan Kemampuan Belajar Siswa Bidang Studi Al-Qur'an Hadits Pada Siswa Mtss Darul Huda Kota Langsa Jurnal Al-Ikhtibar". (Jurnal Ilmu Pendidikan) Vol. 3 No. 2 Tahun 201687.

Fitriana, K. 2013. Meningkatkan Prestasi Belajar IPA Melaui Strategi Card Sort Pada Siswa Kelas IV MI Ma'arif Mendongan Kecamatan Bandungan Kabupaten Semarang Tahun Ajran 2013/2014. Skripsi.Perpus

IAIN Salatiga.http://perpus.iainsalatiga.ac.id/docfiles/fulltext/1c4fe96867e59051.pdf. Diakses 21 juni 2017 Pukul 19.21 WIB. 
Hamdani. 2011. Strategi Belajar Mengajar. Bandung: Pustaka Setia.

Hamruni. 2012. Strategi Pembelajaran. Yogyakarta: Insan Madani.

Haryanto. 2011. Strategi Pembelajaran Aktif Card Sort Dan Index Card Match Terhadap Prestasi Belajar Getaran Dan Gelombang. Semarang. IKIP PGRI. JP2F, Volume 2 Nomor 2 September 2011. Diakses 20 September 2018 Pukul 09.44 WIB.

Kamus Besar Bahasa Indonesia Edisi V. 2016. Tentang Prestasi Belajar.

Kustandi, C., \& Sutjipto, B. 2013. Media Pembelajaran Manual dan Digital. Bogor: Ghalia Indonesia.

Pendidikan, B. S. 2006. Kurikulum Tingkat Satuan Pendidikan. Jakarta: Departemen Pendidikan Nasional.

Rositawaty, S., \& Muharam, A. 2008. Senang Belaja rIlmu Pengetahuan Alam 4 untuk Sekolah Dasar/Madrasah ibtidaiyah Kelas IV. Jakarta: Departemen Pendidikan Nasional.

Sakdiyah, Siti Halimatus \& Yuli Ifana Sari. 2016." Penerapan Model Pembelajaran Card Sort Untuk Meningkatkan Keaktifan Siswa Kelas V Se-Gugus Kebonsari Kecamatan Sukun Kota Malang”. Jurnal Pendidikan: Teori, Penelitian, dan Pengembangan Volume: 1 Nomor: 10 Bulan Oktober Tahun 2016 Halaman: 2004-2009.

Silberman, Melvin. 2013. Pembelajaran Aktif 101 Strategi untuk Mengajar Secara Aktif. Jakarta Barat: Indeks.

Slameto. 2010. Belajar \& Faktor-Faktor yang Mempengaruhi. Jakarta: Rineka Cipta.

Sudjana. 2005. Metode Statistika. Bandung: PT Tarsito.

Sugiyono. 2015. Metode Penelitian Kuntitatif, Kualitatif, dan R\&D. Bandung: Alfabeta.

Syah, Muhibbin. 2006. Psikologi Belajar. Jakarta: PT Raja Grafindo Persada.

Syaodih, Nana. 2016. Metode Penelitian Pendidikan. Bandung: PT Remaja.

Undang-UndangNo. 20 Tahun 2003. Tentang SISDIKNAS (Sistem Pendidikan Nasional). Jakarta: Grafika.

Zaini, H., Munthe, B., \& Ariyani, S. A. 2008. Strategi Pembelajaran Aktif. Yogyakarta: Pustaka Insan Madani. 